\title{
A Taxonomy for Data Ecosystems
}

\author{
Joshua Gelhaar \\ Fraunhofer ISST \\ joshua.gelhaar@isst.fraunhofer.de
}

\author{
Tobias Groß \\ Fraunhofer ISST \\ tobias.gross@isst.fraunhofer.de
}

\author{
Boris Otto \\ Fraunhofer ISST \\ boris.otto@isst.fraunhofer.de
}

\begin{abstract}
In the increasingly interconnected business world, economic value is less and less created by one company alone but rather through the combination and enrichment of data by various actors in so-called data ecosystems. The research field around data ecosystems is, however, still in its infancy. With this study, we want to address this issue and contribute to a deeper understanding of data ecosystems. Therefore, we develop a taxonomy for data ecosystems which is grounded both theoretically through the linkage to the scientific knowledge base and empirically through the analyses of data ecosystem use cases. The resulting taxonomy consists of key dimensions and characteristics of data ecosystems and contributes to a better scientific understanding of this concept. Practitioners can use the taxonomy as an instrument to further understand, design and manage the data ecosystems their organizations are involved in.
\end{abstract}

\section{Introduction}

The increasing number of digital technologies makes data a key driver of the digital economy [1]. The development of new methods for data processing and analysis leads to changes in existing businesses as well as to the emergence of new business models [2, $3]$. Furthermore, in today's networked business world data-driven innovation and creation of economic value is less and less created by a single organization or in traditional value chains $[4,5]$. Instead, various data sources from different organizations are combined and enriched in cross-industry, socio-technical networks so-called data ecosystems [5, 6, 7]. Some authors believe that in today's age, involvement in ecosystems is no longer a choice, but rather a necessity for companies to unlock the benefits of data sharing $[6,8$, 9]. This is confirmed by the management consulting firm McKinsey who believes that ecosystems will generate 30 percent of the global gross domestic product by 2025 [10]. However, while data ecosystems are gaining in importance many companies still refuse or fail to share their data and thus are unable to utilize the offerings of data ecosystems $[11,12,13]$. One reason for this is that the research of data ecosystems is still in its infancy, which results in a lack of commonly accepted theories, definitions, and models [14]. In their systematic review of the data ecosystem literature [14] advise conducting further research to gain more knowledge about the characteristics of data ecosystems. In particular, according to [6], researchers and practitioners would benefit from an effective organization and categorization of existing knowledge about data ecosystems. To the best of our knowledge, there is yet no scientific publication addressing the authors' calls in general, or in particular no formal taxonomy showing the key dimensions and characteristics of data ecosystems.

Taxonomies generally help researchers and practitioners to understand and analyze complex domains by providing a structure and an organization of knowledge for the respective research field $[15,16]$. Additionally, a taxonomy can be a first step on the way towards the development of a rigorous theory [17]. We, therefore, hypothesize that the development of a taxonomy for data ecosystems would help to understand data ecosystems in its totality and in a more general way and be a contribution to the current body of knowledge $[15,18]$. Thus, to address the abovementioned research gap and to contribute to a deeper understanding of the emerging and developing research field around data ecosystems we aim to answer the following research question in this paper:

Research Question (RQ): What are the key dimensions and characteristics of data ecosystems?

To answer the RQ we develop a taxonomy for data ecosystems using the well-used and structured method by [16]. The development of the taxonomy pursues the goal of identifying common characteristics of data ecosystems and making them distinguishable in a consistent taxonomy. Following the method of [16], the process of taxonomy development is carried out successively: First, we analyze previous data ecosystems classifications and related taxonomies. 
Next, we perform a systematic literature review to complement the findings from prior characterizations by analyzing additional relevant publications on data ecosystems. Third, we derive characteristics by analyzing eighteen data ecosystem use cases to develop a taxonomy with empirical stability and relevance [19]. The triangulation of previous classifications, extant scientific literature, and use cases enables us to develop a taxonomy for data ecosystems with a high relevance for researchers and practitioners. The remainder of this paper is structured as follows: After the introduction, we proceed with outlining the theoretical background on data ecosystems and review related characterization efforts. In section 3, we outline our research approach by describing the taxonomy development method and process. Our developed taxonomy for data ecosystems is presented in section 4. Finally, in section 5, we discuss the implications of our research for theory and practice, limitations, and future research.

\section{Research background}

\subsection{Data ecosystems}

The ecosystem concept was introduced by [20], who defined it as follows: "But the more fundamental conception is, as it seems to me, the whole system, including not only the organism-complex, but also the whole complex of physical factors in the widest sense." $[21,22]$. Initially, the term was used in biology to describe the interactions between organisms of different species and their environment as an integrated system $[23,24]$. Since then new research streams have emerged in which the specific characteristics of the biological ecosystem concept have been transferred to other research contexts [24, 25]. One of the most famous analogies was coined by [26] with the concept of "business ecosystems" [27]. [28] defines a business ecosystem as an "economic community" consisting of interacting organizations including producers, suppliers, competitors, and other various stakeholders. The community aims to create new innovative products or services for the customers who are themselves members of the business ecosystem $[26,28]$. Thereafter the ecosystem concept has been applied to other research areas e.g. digital ecosystems [9], software ecosystems [29], or platform ecosystems [30]. However, some of these ecosystem concepts overlap both in definition and content [31]. For example are digital ecosystems regarded as "digital versions" of business ecosystems and data ecosystems as a special kind of digital ecosystems [32, $33,34]$. The various areas of application share, however, the commonality that the ecosystem concept is used to describe diverse interactions between several actors who contribute to the construction or manipulation of a resource (e.g. business object, service, software or platform) through common activities $[6,11]$. In data ecosystems these focused objects are data and their related technologies [6, 35]. On that basis and following other authors $([14,36])$ we see the focus of data ecosystems in the cross-actor generation, processing, and use of data with the goal to create added value for all actors involved.

Due to the different relationships of the actors to the resource, which is in the focus of the ecosystem, various roles with different functions in the ecosystem develop [37]. [6] define a role as a function performed by an actor within the ecosystem. Characteristic for some ecosystem types is the existence of a central role, often referred to as "keystone" actor, which can be largely responsible for the survival and success of the ecosystem $[21,38,39]$.

Apart from the existence of a keystone actor, most ecosystems concepts have other specific similarities and characteristics in common which illustrate the differences to traditional value chains and industrial structures $[21,34,40]$. One premise is the lack of clear boundaries of the ecosystem which leads to different degrees of dependency and relationships between the actors and ultimately to a heterogeneous and alternating member base [24, 35]. Another shared characteristic between the ecosystem concepts is referred to as "co-evolution" [24, 41]. It describes the process of continuous, interdependent development of multiple ecosystem actors [41, 42]. This is due to the fact that the actors in an ecosystem have cooperative and competitive relationships simultaneously - also known as coopetition [21, 26, 43]. The characteristic "platform" is often described as a further similarity between different ecosystem concepts $[14,34]$. It describes "platforms" as services, tools, or technologies that ecosystem actors use to contribute to the value creation of the ecosystem [33].

\subsection{Related taxonomies}

There have already been some efforts in the academic literature to describe the characteristics of data ecosystems, e.g. in the form of typologies or taxonomies. In literature, the two terms typology and taxonomy are often used synonymously [16, 44]. However, one could argue that typologies are conceptually grounded [45], while taxonomies are developed empirically [46, 47]. According to [47], taxonomic classifications are useful in the Information Systems (IS) field because of their practical relevance and their empirical evaluation. In the following we 
take a closer look at data ecosystem-related taxonomies and systemizations.

[48] developed a framework of specific criteria for a successful establishment of data ecosystems in the humanitarian sector. On that basis, we argue that the authors created a framework for the design and coordination of data ecosystems in a specific sector and not a taxonomy for data ecosystems in general which we aim to develop in this paper.

Regarding the solutions of public problems by making data accessible, [49] developed a taxonomy for so-called "data collaboratives". The authors define data collaboratives as cross-sector collaboration initiatives for the purpose of addressing a societal challenge through the leverage of data [49]. Although [50] see data collaboratives as segmentation of data ecosystems, we argue that the concept of data collaboratives misses some important characteristics of the ecosystem concept such as "co-evolution" or the organizational structures $[6,14]$.

Based on the works of [48] and [49], [50] developed a framework to characterize data ecosystems based on five dimensions. This framework is, however, focused on the description of data ecosystems in developing countries. We would argue that a framework with a focus on developing countries does not characterize data ecosystems in general, since data ecosystems can emerge in different domains [14] and developing countries have a data-poor context [50].

Focusing on the design of data ecosystems and the relationships among their participants, [51] developed a typology for data ecosystems with the two key criteria resource control and interdependence. This typology, like typologies in general, helps to differentiate between idealized types of data ecosystems but is less assistant when classifying realworld data ecosystems [21], which is the goal of this study. In order to discuss data ecosystem coordination and possibilities for their composition, [52] propose characteristics for the design of data ecosystems. All design dimensions are, however, only twodimensional which we argue don't reflect the multidimensional character of data ecosystems [36]. Furthermore, the authors give no information about the method they used to develop their design characteristics. Alluding to the multidimensional character of data ecosystems as mentioned above, [36] developed a morphology for data ecosystems using the Service-Dominant Logic (SDL) [53] framework as research perspective. The morphology is, however, focused on the manufacturing industry, which is just one domain in which data ecosystems can emerge [14]. Despite this particular focus, [36] served as a good basis for the first iteration in our taxonomy development process. Table 1 gives a summary of the data ecosystem-related taxonomies and systemizations described above.

Table 1. Examples of data ecosystemsrelated characterizations and systemizations.

\begin{tabular}{|l|l|l|}
\hline Source & Type & Description \\
\hline$[48]$ & $\begin{array}{l}\text { Success } \\
\text { criteria }\end{array}$ & $\begin{array}{l}\text { Framework for } \\
\text { data ecosystems } \\
\text { in the } \\
\text { humanitarian } \\
\text { sector }\end{array}$ \\
\hline$[49]$ & Taxonomy & $\begin{array}{l}\text { Taxonomy of } \\
\text { data } \\
\text { collaboratives }\end{array}$ \\
\hline$[50]$ & Characteristics & $\begin{array}{l}\text { Framework for } \\
\text { data ecosystems } \\
\text { in developing } \\
\text { countries }\end{array}$ \\
\hline$[51]$ & Typology & $\begin{array}{l}\text { Typology of } \\
\text { data ecosystems }\end{array}$ \\
\hline$[52]$ & $\begin{array}{l}\text { Design } \\
\text { characteristics }\end{array}$ & $\begin{array}{l}\text { Characteristics } \\
\text { for the design of } \\
\text { data ecosystem }\end{array}$ \\
\hline$[36]$ & Morphology & $\begin{array}{l}\text { Morphology of } \\
\text { data ecosystems } \\
\text { with a SDL } \\
\text { perspective }\end{array}$ \\
\hline
\end{tabular}

\section{Research approach}

\subsection{Taxonomy development method}

For the taxonomy development, we adopted the approach from [16] to the context of our study. This method is well-established in the IS research and has been frequently used in high-ranking journal articles and conference proceedings. The authors provide a taxonomy development approach, which is divided into distinct stages (see Figure 1). In the first stage, one is to define a meta-characteristic and ending conditions that are specific to the purpose the taxonomy strives to achieve. Subsequently, the dimensions of the taxonomy, which need to address the meta-characteristics, are developed. The development can either be done through inductive or deductive iterations. In the first approach, dimensions and characteristics result from a conceptual-toempirical (C2E) design and are derived from empiricism. The empirical-to-conceptual (E2C) approach focuses on the deduction of dimensions and characteristics from the scientific knowledge base. In the last stage, the taxonomy is evaluated against the ending conditions. 


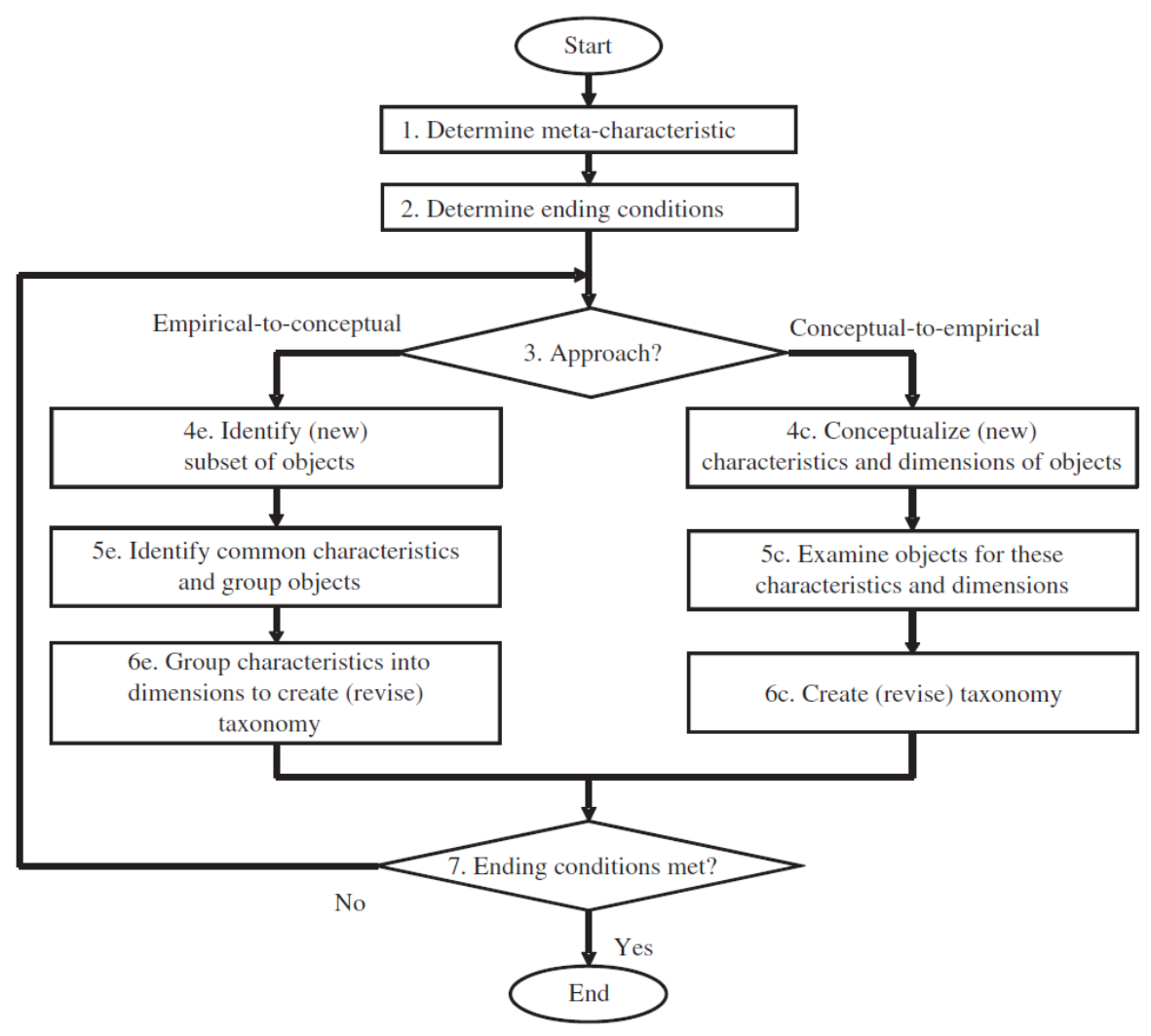

Figure 1. Taxonomy development method by [16]

\subsection{Taxonomy development process}

Meta-characteristic: In order to contribute to the scientific understanding of data ecosystems, the main goal of our taxonomy is to characterize data ecosystems in general. Therefore, we defined "keycharacteristics of data ecosystems" as the metacharacteristic for our taxonomy. This metacharacteristic is the basis for the identification of further dimensions and characteristics.

Meta-dimensions: Our taxonomy has the goal to characterize the concept of data ecosystems in a more general way to include as many heterogeneous data ecosystems as possible [15]. Therefore, it should be more generally designed to cover a large possible field of observation [15,44]. Following [52] and in the analysis previous classifications, it became obvious that data ecosystems can be examined from the three perspectives economic, technical, and governance. Following previous taxonomies (e. g. [44], [54], or [55]) we chose these three perspectives as metadimensions for our study.

First Iteration (E2C): In the first iteration, we derived dimensions and characteristics from previous classifications. We consolidated the in section 2.2 described data ecosystem-related taxonomies and systemizations to serve as a basis for our study. Noteworthy are the works of [14], [36] and [52], which formed, due to their comprehensiveness, a good foundation for our data ecosystem taxonomy.

Second Iteration (C2E): In the second iteration, we reviewed the existing literature on data ecosystems and followed the approach described by [56]. Following the research question, we searched in the Scopus and the AIS eLibrary databases using the search string "data ecosystem" OR "data-driven ecosystem" OR "data-based ecosystem", as these strings were seen as synonyms by the authors. The results were limited to only peer-reviewed and in the English language literature. This resulted in 357 as an initial set of papers. During a first iteration, the results were scanned regarding title, abstract, and keywords for the relevance of data ecosystems. During a second iteration, we searched forward and backward [56]. The result was 28 relevant articles. In addition, we added the 29 articles from a recent systematic review of the data ecosystems literature [14], where the authors selected and reviewed articles based on further searching keywords (e.g. "open data ecosystem" and "big data ecosystem") in further prominent bibliographic databases (e.g. IEEE and ACM). 
Excluding the 7 duplicate articles due to the overlap between the two collections, in total $50(=28+29-7)$ articles formed a good sample of extant knowledge about data ecosystems.

Third Iteration (E2C): For the third iteration, we again chose the empirical-to-conceptual approach. Through the collection of real-world use cases of data ecosystems, we aimed to extend our findings from literature and provide further empirical evidence. We analyzed the eleven use cases described by [57] to further develop our taxonomy.

Fourth Iteration (E2C): Because not all ending conditions were fulfilled in the third iteration, we conducted a last empirical-to-conceptual approach. We analyzed the seven data ecosystem use cases described by [32] and the two use cases described by [36]. Through the selection of use case descriptions from different sources, we aimed to increase the representativeness of the sample.

Ending Conditions: After the fourth iteration, all objective and subjective ending conditions proposed by [16] were fulfilled as follows: 1) All papers from the sample of the literature review and use cases have been examined. 2) In the last iteration, no object was merged with a similar object or split into multiple objects. 3) Each characteristic of each dimension could be classified with at least one object. 4) No new dimensions or characteristics were added in the last iteration. 5) Neither were dimensions or characteristics merged or split in the last iteration. 6) Each dimension is unique and not duplicated. 7) Every characteristic is unique within its dimension. 8) Each combination of characteristics is unique and not repeated. 9) The taxonomy is concise since no unnecessary dimensions or characteristics were included. 10) There are enough dimensions and characteristics to differentiate every object from each other (robustness). 11) All objects can be classified in the taxonomy, therefore it is comprehensive. 12) The taxonomy is extendible because new dimensions and characteristics can easily be added. 13) Lastly, the taxonomy provides valuable information but non-redundant information for the characterization of data ecosystems (explanatory).

\section{A taxonomy for data ecosystems}

In this section, we present the final taxonomy in detail, which we derived from the entire taxonomy development process. The taxonomy serves as an answer to the research question of this study, as it identifies the key dimensions and characteristics of data ecosystems. The taxonomy consists of three meta-dimensions, seven dimensions with eighteen characteristics (see Table 2). In addition to the individual dimensions and the corresponding characteristics, the right column shows whether a characteristic is exclusive $(E)$ or non-exclusive $(N)$. We visualize the taxonomy as a morphological box as this is a common type of taxonomy visualization [58] and it generally illustrates the set of relationships contained in a problem complex in an intuitive way [59].

\subsection{Meta-dimension: Economic}

The first meta-dimension is Economic. It considers dimensions from a business-model and competitive dynamics perspective of data ecosystems [32] which is an important perspective to take when analyzing data ecosystem [14].

The dimension Domain relates to the environment or setting where a data ecosystem emerges and therefore which data are in the focus of the ecosystem [14]. As noted by [14] data ecosystems can emerge in the scientific domain (see e.g. [57] or [60]), the governmental domain (see e.g. [61] or [62]) or in an industry domain (see e.g. [36] or [63]). Although the term open data ecosystem also exists in the literature, it should be noted that open data can play a role in all three of these domains and therefore does not constitute a domain of its own $[61,62]$. This dimension is non-exclusive since one premise of the data ecosystem concept are blurred boundaries and overlapping industries [14, 21, 52].

The dimension Purpose describes the strategic focus the data ecosystem is aiming for. The added value of data ecosystems does not come from sharing data alone but rather from the (re-)usage of data by the different, independent actors [32]. One main goal of the data sharing in a data ecosystem can be the creation of innovation [64, 65], which can, for example, result in new digital value propositions [32]. The second possible objective of data ecosystems is the interaction between the actors $[14,66,67]$. These interactions can consist of communication or the transfer and sharing of knowledge and experience $[32,51,63]$. The third possible purpose of data ecosystems, especially for platform-based data ecosystems, is the facilitation of transactions between the data ecosystem actors [32, $68,69]$. Here, the platform or ecosystem provides interfaces to enable transactions between organizations that might otherwise not be able to complete transactions [70]. Since a data ecosystem can have several purposes at the same time the dimension Purpose is non-exclusive. 
Table 2. Final taxonomy for data ecosystems visualized as a morphological box

\begin{tabular}{|c|c|c|c|c|c|c|}
\hline $\begin{array}{c}\text { Meta- } \\
\text { dimension }\end{array}$ & Dimension & \multicolumn{4}{|c|}{ Characteristics } & $\mathrm{E} / \mathrm{N}$ \\
\hline \multirow{3}{*}{ Economic } & Domain & Scientific & \multicolumn{2}{|c|}{ Government } & Industry & $\mathrm{N}$ \\
\hline & Purpose & Innovation & \multicolumn{2}{|c|}{ Interaction } & Transaction & $\mathrm{N}$ \\
\hline & Organization & Keystone-centric & Platform-centric & $\begin{array}{c}\text { Marketplace- } \\
\text { based }\end{array}$ & Decentralized & $\mathrm{E}$ \\
\hline \multirow{2}{*}{ Technical } & Infrastructure & \multicolumn{2}{|c|}{ Centralized } & \multicolumn{2}{|c|}{ Distributed } & $\mathrm{E}$ \\
\hline & Openness & \multicolumn{2}{|c|}{ Open } & \multicolumn{2}{|c|}{ Closed } & $\mathrm{E}$ \\
\hline \multirow{2}{*}{ Governance } & Interdependence & \multicolumn{2}{|c|}{ Tightly Coupled } & \multicolumn{2}{|c|}{ Loosely Coupled } & $\mathrm{E}$ \\
\hline & Control & \multicolumn{2}{|c|}{ Central } & \multicolumn{2}{|c|}{ Decentral } & $\mathrm{E}$ \\
\hline
\end{tabular}

In connection with the previous two dimensions is the dimension Organization. It refers to the different kinds of relationships, interactions, and organization of the actors which form a data ecosystem [14, 32, 71, 72]. In our research process we found the following forms of data ecosystems organizational structure: Keystone-centric, platform-centric, marketplacebased, and decentralized.

A keystone-centered structure can be seen when the actors are organized around a keystone actor (see e.g. [62]) who is directly or indirectly responsible for providing a large part of the data in the ecosystem [6]. In a platform-centric data ecosystem organization structure a platform provides an infrastructure and services to support the sharing and usage of data within the ecosystem (see e.g. [36]). The release of data on a platform can reduce the cost for data provision and mitigate interoperability and usability issues [14, 73]. A marketplace-based structure (see e.g. [57] or [63]) provides, besides a technical platform, additional components and functions, e.g. business models, applications and rules and services for data sharing, as part of the data ecosystem infrastructure [63]. In addition to these more centrally organized forms of organization, we observed data ecosystems in our study that have a more decentralized, distributed form of organization (see e.g. [57]). These data ecosystems are characterized by the absence of a central actor but are connected by their common goal of jointly creating value [14, 57]. Although the organization form of a data ecosystem can change over time [52], we argue that a data ecosystem can only have one dominant form of organization at a time, which makes the dimension mutually exclusive.

\subsection{Meta-dimension: Technical}

The second meta-dimension is Technical. It refers to the characteristics of the technical architecture of the data ecosystem $[36,50]$.

The Infrastructure dimension specifies the main technical infrastructure which is used to share data within the data ecosystem $[32,50]$. The collaborative use of data can, on the one hand, take place through a central infrastructure, e.g. a proprietary platform $[32$, 52]. See for example [36] where an organization from the manufacturing industry wants to develop an analytics platform to offer data-driven services to customers worldwide. On the other hand, the data ecosystem can use a distributed infrastructure for data sharing through the use of distributed ledger or a peerto-peer technologies (e.g. the International Data Space) $[32,57]$. Data ecosystem use cases using a distributed infrastructure are described by [57]. This dimension is mutually exclusive.

Openness concerns the degree of access to the data ecosystem. This can either be open or closed $[32,36]$. A data ecosystem which is open is free for everyone to join $[32,50]$. A closed data ecosystem, however, has barriers to entry. These entry barriers can be technical barriers, e.g. the need for a proprietary technical standard or technology, or legal barriers, such as a required membership or multi-lateral contracts $[32$, $50,74]$. This dimension is mutually exclusive as well.

\subsection{Meta-dimension: Governance}

The third meta-dimension is Governance. It regards data ownership and actor dependency aspects within the data ecosystem $[32,36,51,75]$.

The degree to which ecosystem actors are connected and dependent on each other is described by the dimension Interdependence [51]. Similar to actor 
interactions and relationships in other ecosystems [21, 41], actors in data ecosystems can be tightly or loosely coupled [51].

The dimension Control refers to the control of the essential data resources in the data ecosystem [51]. The key data resources can be controlled by a central actor, e.g. a keystone actor, or can be decentralized and therefore spread across the multiple actors in the data ecosystem $[21,32,51]$. This decentralized data distribution and resource sharing can take place, for example, via shared digital twins technologies or via alliance-driven platform architectures [32, 76]. A decentralized control as a governance mechanism within a data ecosystem generally results in data owners retaining more control and sovereignty over their data $[32,57,77]$.

\section{Conclusion}

Through the application of the taxonomy development method by [16] we developed a taxonomy for data ecosystems. The taxonomy consists of seven key dimensions and eighteen characteristics of data ecosystems and therefore gives an answer to the research question of this paper.

From our results we can draw several implications for theory and practice. Regarding scientific contributions, our work contributes to a deeper understanding of the still relatively new and unexplored research field around data ecosystems. Our taxonomy, which was derived from the scientific knowledge base and from empirical use cases, aims to expand the existing body of knowledge and specify the common understandings and definitions of data ecosystems. The results of this study serve as a tool to describe data ecosystems in-depth and explicitly and can, therefore, help researchers to distinguish between different data ecosystems [17]. Furthermore, our results can be the basis for the development of engineering methods and processes for the management and development of data ecosystems which are still missing in the scientific literature [14]. Finally, our taxonomy is a first step towards the development of theories and fundamental concepts of data ecosystems, which are similarly missing in the scientific literature $[14,17]$.

As for managerial contributions, the developed taxonomy provides an instrument to analyze and describe the structure and characteristics of data ecosystems. The taxonomy can, firstly, be used to better understand the ecosystem in which an organization is already involved. Secondly, the taxonomy can then be utilized by practitioners to actively shape the ecosystem to their own advantage.
A better understanding of the surrounding data ecosystem helps organizations to better manage the ecosystem in their favor and generate more value from it [14]. Finally, the taxonomy can be leveraged by organizations to build and design new ecosystems with the goal of utilizing the advantages of cross-company data sharing in data ecosystems [17].

Our study is, naturally, limited by a number of limitations that must be taken into account when interpreting the results. Due to the continuing rapid technological and organizational progress in the digitization and since it is still an under-explored research area [1, 14], the concepts around data ecosystems are constantly evolving. Thus, our taxonomy is a time-bound snapshot that needs to be updated frequently to remain relevant and to consider new dimensions and features produced by the progress of digitization. Secondly, the lack of a well-accepted definition of data ecosystems makes it difficult to distinguish between related concepts, e.g. alliances and networks, and related ecosystem concepts, e.g. digital and platform ecosystems [14]. Finally, although the taxonomy is based both on the analysis of the scientific literature and on the analysis of empirical use cases of data ecosystems, the data collection itself is open to interpretation, which is why other researchers might derive other dimensions and characteristics depending on their personal influences, preferences and biases. Regarding the selection of literature and use cases, there is also a limitation regarding the extent and scope of the taxonomy. Although the motivation of this study was to develop a more general and cross-sectoral taxonomy, it should be noted that most of the literature examined comes from the IS field and may therefore represent a limitation and could be a bias to this research area. Also the empirical samples examined probably do not cover all domains in which ecosystems can develop, which is why the transferability of the results cannot be fully guaranteed and instead leaves room for further practice-oriented research.

In general, the limitations show possibilities for future research avenues. One possible next step, which is common in IS taxonomy research [19], is the derivation of archetypical patterns for data ecosystems. Based on the identified archetypes, it could be investigated whether some archetypes are more successful than others, from which design principles for data ecosystems could be derived. Furthermore, data ecosystems that use distributed technologies, such as distributed ledgers or peer-topeer technologies, are not yet well studied due to the novelty of the technologies and thus promise further research opportunities $[57,76]$. We therefore assume that further dimensions or characteristics may emerge, 
especially regarding the dimensions Infrastructure and Control. This study could, for instance, not identify any characteristics regarding incentive systems and the distribution of benefits within the ecosystem. However, these issues are becoming increasingly important, especially in distributed and decentralized data ecosystems [32, 51].

\section{References}

[1] Azkan, C., M. Spiekermann, and H. Goecke, "Uncovering Research Streams in the Data Economy Using Text Mining Algorithms", Technology Innovation Management Review, 9(11), 2019, pp. 62-74.

[2] Veit, D., E. Clemons, A. Benlian, P. Buxmann, T. Hess, D. Kundisch, J.M. Leimeister, P. Loos, and M. Spann, "Business Models: An Information Systems Research Agenda", Business \& Information Systems Engineering, 6(1), 2014, pp. 45-53.

[3] Möller, F., M. Stachon, C. Hoffmann, H. Bauhaus, and B. Otto, "Data-driven Business Models in Logistics: A Taxonomy of Optimization and Visibility Services", in Proceedings of the 53rd Hawaii International Conference on System Sciences. 2020.

[4] Rantanen, M.M., S. Hyrynsalmi, and S.M. Hyrynsalmi, "Towards Ethical Data Ecosystems: A Literature Study", in Proceedings, 2019 IEEE International Conference on Engineering, Technology and Innovation (ICE/ITMC). 2019.

[5] Hein, A., J. Weking, M. Schreieck, M. Wiesche, M. Böhm, and H. Krcmar, "Value co-creation practices in business-to-business platform ecosystems", Electronic Markets, 29(3), 2019, pp. 503-518.

[6] Oliveira, M.I.S. and B.F. Lóscio, "What is a data ecosystem?", in Proceedings of the 19th Annual International Conference on Digital Government Research, Delft, Netherlands, May 30-June 1. 2018. ACM: New York, USA.

[7] Yoo, Y., O. Henfridsson, and K. Lyytinen, "Research Commentary - The New Organizing Logic of Digital Innovation: An Agenda for Information Systems Research", Information Systems Research, 21(4), 2010, pp. 724-735.

[8] Llewellyn, D.W.T. and A. Erkko, "The processes of ecosystem emergence", Academy of Management Proceedings, 2015.

[9] Selander, L., O. Henfridsson, and F. Svahn, "Capability Search and Redeem across Digital Ecosystems", Journal of Information Technology, 28(3), 2013, pp. 183-197.

[10] https://www.mckinsey.com/industries/financialservices/our-insights/the-rise-of-ecosystems-and-platformswhat-role-can-insurers-play-and-how-can-they-get-started.

[11] Heimstädt, M., F. Saunderson, and T. Heath, "From Toddler to Teen: Growth of an Open Data Ecosystem",
JeDEM - eJournal of eDemocracy and Open Government, 6(2), 2014, pp. 123-135.

[12] Kaiser, C., A. Stocker, and M. Fellmann, "Understanding Data-driven Service Ecosystems in the Automotive Domain", in Proceedings of the 25th Americas Conference on Information Systems, AMCIS. 2019.

[13] Prieelle, F. de, M. de Reuver, and J. Rezaei, "The Role of Ecosystem Data Governance in Adoption of Data Platforms by Internet-of-Things Data Providers: Case of Dutch Horticulture Industry", IEEE Transactions on Engineering Management, 2020, pp. 1-11.

[14] Oliveira, M.I.S., G.d.F. Barros Lima, and B.F. Lóscio, "Investigations into Data Ecosystems: a systematic mapping study", Knowledge and Information Systems, 2019.

[15] Glass, R.L. and I. Vessey, "Contemporary applicationdomain taxonomies", IEEE Software, 12(4), 1995, pp. 6376.

[16] Nickerson, R.C., U. Varshney, and J. Muntermann, "A method for taxonomy development and its application in information systems", European Journal of Information Systems, 22(3), 2013, pp. 336-359.

[17] Williams, K., S. Chatterjee, and M. Rossi, "Design of Emerging Digital Services: A Taxonomy", in Design Research in Information Systems, A. Hevner and S. Chatterjee, Editors. 2010. Springer US: Boston, MA.

[18] Labazova, O., T. Dehling, and A. Sunyaev, "From Hype to Reality: A Taxonomy of Blockchain Applications", in Proceedings of the 52nd Hawaii International Conference on System Sciences. 2019.

[19] Azkan, C., L. Iggena, I. Gür, F.O. Möller, and B. Otto, "A Taxonomy for Data-Driven Services in Manufacturing Industries", in PACIS 2020 Proceedings. 2020.

[20] Tansley, A.G., "The Use and Abuse of Vegetational Concepts and Terms.”", Ecology, 16(3), 1935, pp. 284307.

[21] Guggenberger, T.M., F. Möller, T. Haarhaus, I. Gür, and B. Otto, "Ecosystem Types in Information Systems", in Proceedings of the 28th European Conference on Information Systems (ECIS). 2020.

[22] Richter, D.d. and S.A. Billings, "'One physical system': Tansley's ecosystem as Earth's critical zone", The New phytologist, 206(3), 2015, pp. 900-912.

[23] Chapin III, F.S., P. A. Matson, and P. M. Vitousek, "The ecosystem concept", in Principles of Terrestrial Ecosystem Ecology, F.S. Chapin III, Editor. 2014. Springer: Berlin, Germany.

[24] Jacobides, M.G., C. Cennamo, and A. Gawer, "Towards a theory of ecosystems", Strategic Management Journal, 39(8), 2018, pp. 2255-2276.

[25] Wang, P., "Theorizing digital innovation ecosystems: a multilevel ecological framework", in Proceedings of the 
27th European Conference on Information Systems (ECIS), Stockholm \& Uppsala, Sweden, June 8-14. 2019.

[26] Moore, J.F., "Predators and Prey: A New Ecology of Competition", Harvard Business Review, 71(3), 1993, pp. 75-86.

[27] Nachira, F., A. Nicolai, P. Dini, M. Le Louarn, and L.R. Leon, eds., Digital Business Ecosystems, Publications Office, Luxembourg, 2007.

[28] Moore, J.F., The death of competition: Leadership and strategy in the age of business ecosystems, Harper Paperbacks, New York, USA, 1996.

[29] Jansen, R.L., A. Finkelstein, and S. Brinkkemper, "Business Network Management as a Survival Strategy: A Tale of Two Software Ecosystems", Proceedings of the 1st International Workshop on Software Ecosystems, 2009, pp. 34-48.

[30] Tiwana, A., B. Konsynski, and A.A. Bush, "Research Commentary: Platform Evolution: Coevolution of Platform Architecture, Governance, and Environmental Dynamics", Information Systems Research, 21(4), 2010, pp. 675-687.

[31] Hyrynsalmi, S. and S.M. Hyrynsalmi, "Ecosystem: A Zombie Category?", in Proceedings, 2019 IEEE International Conference on Engineering, Technology and Innovation (ICE/ITMC). 2019.

[32] Cappiello, C., A. Gal, M. Jarke, and J. Rehof, "Data Ecosystems: Sovereign Data Exchange among Organizations: Report from Dagstuhl Seminar 19391", Dagstuhl Reports, 9(9), 2019, pp. 66-134.

[33] Senyo, P.K., K. Liu, and J. Effah, "Digital business ecosystem: Literature review and a framework for future research", International Journal of Information Management, 47, 2019, pp. 52-64.

[34] Senyo, P.K., K. Liu, and J. Effah, "Unpacking the role of politicalwill in digital business ecosystem development for socioeconomic benefits", in Proceedings of the 27th European Conference on Information Systems (ECIS), Stockholm \& Uppsala, Sweden, June 8-14. 2019.

[35] Nischak, F., A. Hanelt, and L.M. Kolbe, "Unraveling the Interaction of Information Systems and Ecosystems - A Comprehensive Classification of Literature", in Proceedings of the Thirty Eighth International Conference on Information Systems, ICIS 2017. 2017.

[36] Azkan, C., F. Möller, L. Meisel, and B. Otto, "Service Dominant Logic Perspective on Data Ecosystems - A Case Study based Morphology", in Proceedings of the 28th European Conference on Information Systems (ECIS). 2020.

[37] Hanssen, G.K. and T. Dybå, "Theoretical foundations of software ecosystems", in Proceedings of the Forth International Workshop on Software Ecosystems, Cambridge, USA, 18.06.2012. 2012. CEUR-WS.org.

[38] Iansiti, M. and R. Levien, The Keystone Advantage: What the New Dynamics of Business Ecosystems Mean for
Strategy, Innovation, and Sustainability, Harvard Business School Press, Boston, USA, 2004.

[39] Jansen, S., S. Brinkkemper, J. Souer, and L. Luinenburg, "The open software enterprise model: how open is my software business", in Software Ecosystems: Analyzing and Managing Business Networks in the Software Industry, S. Jansen, S. Brinkkemper, and M.A. Cusumano, Editors. 2013. Edward Elgar Publishing: Cheltenham, UK.

[40] Adner, R., "Ecosystem as Structure", Journal of Management, 43(1), 2017, pp. 39-58.

[41] Rong, K., Y. Lin, B. Li, T. Burström, L. Butel, and J. $\mathrm{Yu}$, "Business ecosystem research agenda: more dynamic, more embedded, and more internationalized", Asian Business \& Management, 17(3), 2018, pp. 167-182.

[42] Moore, J.F., "Business Ecosystems and the View from the Firm", The Antitrust Bulletin, 51(1), 2006, pp. 31-75.

[43] Nalebuff, B.J. and A.M. Brandenburger, "Coopetition: Competitive and cooperative business strategies for the digital economy", Strategy \& Leadership, 25(6), 1997, pp. 28-33.

[44] Möller, F., H. Bauhaus, C. Hoffmann, C. Niess, and B. Otto, "Archetypes of Digital Business Models in Logistics Start-Ups", in Proceedings of the 27th European Conference on Information Systems (ECIS), Stockholm \& Uppsala, Sweden, June 8-14. 2019.

[45] Hambrick, D.C., "Taxonomic Approaches to Studying Strategy: Some Conceptual and Methodological Issues", Journal of Management, 10(1), 1984, pp. 27-41.

[46] Bailey, K.D., Typologies and Taxonomies: An Introduction to Classification Techniques, Sage Publications, Thousand Oaks, 1994.

[47] Rizk, A., B. Bergvall-Kåreborn, and A. Elragal, "Towards a Taxonomy for Data-Driven Digital Services", in Proceedings of the 51st Hawaii International Conference on System Sciences. 2018.

[48] Haak, E., J. Ubacht, M. van den Homberg, S. Cunningham, and B. van den Walle, "A framework for strengthening data ecosystems to serve humanitarian purposes", in Proceedings of the 19th Annual International Conference on Digital Government Research, Delft, Netherlands, May 30-June 1. 2018. ACM: New York, USA.

[49] Susha, I., M. Janssen, and S. Verhulst, "Data Collaboratives as a New Frontier of Cross-Sector Partnerships in the Age of Open Data: Taxonomy Developmen", in Proceedings of the 50th Hawaii International Conference on System Sciences. 2017.

[50] van den Homberg, M. and I. Susha, "Characterizing Data Ecosystems to Support Official Statistics with Open Mapping Data for Reporting on Sustainable Development Goals", ISPRS International Journal of Geo-Information, 7(12), 2018. 
[51] Curry, E. and A. Sheth, "Next-Generation Smart Environments: From System of Systems to Data Ecosystems", IEEE Intelligent Systems, 33(3), 2018, pp. 69-76.

[52] Curry, E. and A. Ojo, "Enabling Knowledge Flows in an Intelligent Systems Data Ecosystem", in Real-time Linked Dataspaces: Enabling Data Ecosystems for Intelligent Systems, E. Curry, Editor. 2020. Springer: Cham, Switzerland.

[53] Vargo, S.L. and R.F. Lusch, "Evolving to a New Dominant Logic for Marketing", Journal of Marketing, 68(1), 2004, pp. 1-17.

[54] Hanelt, A., B. Hildebrandt, and J. Polier, "Uncovering the Role of IS in Business Model Innovation - A Taxonomy-driven Approach to Structure the Field", in Proceedings of the 23rd European Conference on Information Systems, Münster, Germany. 2015.

[55] Remane, G., R.C. Nickerson, A. Hanelt, J.F. Tesch, and L.M. Kolbe, "A Taxonomy of Carsharing Business Models", in Proceedings of the 37th International Conference on Information Systems, Dublin, Ireland. 2016.

[56] Webster, J. and R.T. Watson, "Analyzing the past to prepare for the future: Writing a literature review", MIS Quarterly, 26(2), 2002, pp. xiii-xxiii.

[57] Gelhaar, J. and B. Otto, "Challenges in the Emergence of Data Ecosystems", in PACIS 2020 Proceedings. 2020.

[58] Szopinski, D., T. Schoormann, and D. Kundisch, "Visualize Different: Towards Researching the Fit Between Taxonomy Visualizations and Taxonomy Tasks", in Proceedings of the Wirtschaftsinformatik (WI): Shortpaper, Potsdam, Germany. 2020.

[59] Ritchey, T., "Problem structuring using computeraided morphological analysis", Journal of the Operational Research Society, 57(7), 2006, pp. 792-801.

[60] Lindman, J., T. Kinnari, and M. Rossi, "Business Roles in the Emerging Open-Data Ecosystem", IEEE Software, 33(5), 2016, pp. 54-59.

[61] Zuiderwijk, A., M. Janssen, and C. Davis, "Innovation with open data: Essential elements of open data ecosystems", Information Polity, 19(1,2), 2014, pp. 17-33.

[62] Heimstädt, M., F. Saunderson, and T. Heath, Conceptualizing Open Data ecosystems: A timeline analysis of Open Data development in the UK, Discussion Papers 2014/12, Free University Berlin, School of Business \& Economics., 2014.

[63] Smith, G., H.A. Ofe, and J. Sandberg, "Digital Service Innovation from Open Data: Exploring the Value Proposition of an Open Data Marketplace", in 49th Hawaii International Conference on System Sciences (HICSS). 2016.

[64] Ha, S., S. Lee, and K. Lee, "Standardization requirements analysis on big data in public sector based on potential business models", International Journal of
Software Engineering and Its Applications(8), 2014 pp. 165-172.

[65] Ahmadi Zeleti, F., "Capability Matrix for Open Data", Working Conference on Virtual Enterprises, 2014, pp. 498509.

[66] Zuiderwijk, A., E. Loukis, C. Alexopoulos, M. Janssen, and K. Jeffery, "Elements for the Development of an Open Data Marketplace", in Proceedings of the International Converence for E-Democracy and Open Government. 2014.

[67] Attard, J., F. Orlandi, and S. Auer, "Data Value Networks: Enabling a New Data Ecosystem", in IEEE/WIC/ACM International Conference, Web Intellegence (WI), Editor. 2016. ACM: New York, New York, USA.

[68] Thomas, L.D.W., E. Autio, and D.M. Gann, "Architectural Leverage: Putting Platforms in Context", Academy of Management Perspectives, 28(2), 2014, pp. 198-219.

[69] Koutroumpis, P., A. Leiponen, and L.D.W. Thomas, "Markets for data", Industrial and Corporate Change, 29(3), 2020, pp. 645-660.

[70] McIntyre, D.P. and A. Srinivasan, "Networks, platforms, and strategy: Emerging views and next steps", Strategic Management Journal, 38(1), 2017, pp. 141-160.

[71] Christensen, H.B., K.M. Hansen, M. Kyng, and K. Manikas, "Analysis and design of software ecosystem architectures - Towards the 4S telemedicine ecosystem", Information and Software Technology, 56(11), 2014, pp. 1476-1492.

[72] Manikas, K. and K.M. Hansen, "Software ecosystems - A systematic literature review", Journal of Systems and Software, 86(5), 2013, pp. 1294-1306.

[73] Dawes, S.S., L. Vidiasova, and O. Parkhimovich, "Planning and designing open government data programs: An ecosystem approach", Government Information Quarterly, 33(1), 2016, pp. 15-27.

[74] Janssen, M., Y. Charalabidis, and A. Zuiderwijk, "Benefits, Adoption Barriers and Myths of Open Data and Open Government", Information Systems Management, 29(4), 2012, pp. 258-268.

[75] Lis, D. and B. Otto, "Data Governance in Data Ecosystems - Insights from Organizations", AMCIS 2020 Proceedings, 2020.

[76] Otto, B. and M. Jarke, "Designing a multi-sided data platform: findings from the International Data Spaces case", Electronic Markets, 29(4), 2019, pp. 561-580.

[77] Jarke, M., "Data Sovereignty and the Internet of Production", in Advanced Information Systems Engineering, S. Dustdar, E. Yu, C. Salinesi, D. Rieu, and V. Pant, Editors. 2020. Springer International Publishing: Cham. 